RESEARCHARTICLE

\title{
The Letter: Fidelity in Researcher Positionality to Exhume Dispossessed Voices for Leavy's Concept of Coherence in Feminist Narrative Research
}

\author{
Robin Throne* \\ School of Education, Northcentral University, USA
}

\begin{abstract}
This feminist narrative research explored the fidelity of researcher positionality and Leavy's coherence to consider an archival personal letter from the Sauk warrior Black Hawk's great great daughter, Mary Kakaque, written to John Henry Hauberg, an Illinois philanthropist. Future research is needed to characterize Mary's educational experiences amid an era of cultural annihilation and assimilation within the collective narrative of Hauberg's interpretations, paraphrases, and summaries of Mary's existence, and a phenomenological study to explore Mary's lived experience within the full archival Hauberg collection to consider the constructs of voice or resilience as the lived experiences of Black Hawk's female descendants remain limited. In addition, a critical ethnography may be warranted for ancestral effects of relocation and assimilation from the perspectives of living Black Hawk and Mary's female descendants to contribute a contemporary perspective on voice, culture, and the legacy of land dispossession.
\end{abstract}

Open Access

Citation: Throne, R.The Letter: Fidelity in Researcher Positionality to Exhume Dispossessed Voices for Leavy's Concept of Coherence in Feminist Narrative Research. Gender and Women's Studies. 2018; 2(1):3.

Received: August 14, 2018 Accepted: October 12, 2018 Published: October 26, 2018

Copyright: @ 2018 Throne R. This is an open access article distributed under the terms of the Creative Commons Attribution License, which permits unrestricted use, distribution, and reproduction in any medium, provided the original author and source are credited.

Corresponding author: Robin Throne, School of Education, Northcentral University, USA

E-mail:rthrone@ncu.edu

\section{Keywords}

Researcher positionality, fidelity, coherence, dispossessed voice, acculturation, Sauk/Sac, Black Hawk descendants, narrative research, qualitative inquiry

\section{Introduction}

In 1940, Mary Kakaque, the great great granddaughter of the renowned Sauk Warrior Black Hawk (Ma-ka-tai-me-she-kia-kiak, 1767-1838) wrote to John Henry Hauberg in response to his query about Black Hawk's daughter; yet, only Hauberg's transcribed version (including his successive footnote about her daughter's death) exists among his papers (see Figure 1).

\section{Background}

The confluence of the Mississippi and Sinnissippi (Rock) Rivers (N $41^{\circ} 28.872 \mathrm{~W} 090^{\circ}$ 36.945) was a sacred site to the Sauk/Sac tribe that resided near what became Fort Armstrong, the state of Illinois, the Mississippi River border between Illinois and the lowa territory, and what is now Rock Island, Illinois. Black Hawk and his family were forcibly removed in 1832 to designated Indian Territory (a place name that carries multiple connotations), structures still emblazon the name of Black Hawk on townships, shopping centers, parks, schools, banks, streets and roads, taverns, and even still on his paradoxical Watch Tower'. While their leader and his wife were allowed to remain in lowa, his sons and

\footnotetext{
${ }^{1}$ Black Hawk's (Ma-ka-tai-me-she-kia-kiak, 1767-1838) autobiography and the history of the Black Hawk war, the final 19th century American Indian conflict east of the Mississippi River, has been well documented within the literature. See also Nicholas A. Brown and Sarah E. Kanouse's (2015) provocative photo-essays of the appropriation of Black Hawk in Re-Collecting Black Hawk: Landscape, Memory, and Power in the American Midwest and Simonsen's (2011) cogent illustrations of the Black Hawk exhumation and 19th century representations of the Sac leader.
} 
daughter with their children and other Sauk families were forcibly removed (Simonsen, 2011), and descendants experienced the subsequent multigenerational effects of acculturation and assimilation (Anderson, G. C., 2016; DeMarni et al., 2018).

Even before John Henry Hauberg began a lifelong pursuit of portraying an authentic heritage to Rock Island County (Warren, 2009), Black Hawk shared his version of life story with a trusted white fur trader and the manuscript was later translated by a newspaper editor, which has left some researchers to speculate that it is a work of subjectivity, memory, and imagination, and what is left unsaid or redacted is a device the warrior utilized to protect the Sauk people (Raheja, 2006). The lineage of Black Hawk's daughter was of interest to Hauberg as he attempted to construct the full genealogy of Black Hawk's lineage, of which he was adamant to complete; however, Black Hawk's great-great granddaughter Mary Kakaque, her father, and her grandfather, nor Black Hawk's other descendants, could validate nor directly contribute beyond family story and oral history (see Figure 1). While Hauberg kept prolific notes and journals of his communications and visits with Mary's family over his decades-long construction of Black Hawk's genealogy and the history of Rock Island, primary personal narratives by Mary were limited ${ }^{2}$; therefore, very little primary data exists contemporaneous to Mary's own life experiences. Thus, Mary's letter to Hauberg remains as a singular contemporaneous narrative outside of Hauberg's personal writings by a direct female descendant of Black Hawk, and one example that represents a filtered voice based on the cultural interventions of the dominant culture on a subculture's relocation, acculturation, assimilation, and reconstruction. Hauberg tended to interpret and paraphrase rather than quote or transcribe the words of Mary's family, and Warren (2009) described him as "neither professionally trained nor a reformer obsessed with assimilation" (p. 12), which may have offered a unique positionality as observer within Mary's lifetime. As Griffiths (2017) and others have noted, the white male voice from the dominant or repressive culture often comes from one with degrees or layers of privilege, which often nuance the narrative. This creates a dilemma for the archival narrative researcher who desires to explore lived experience by the departed who can no longer speak for themselves beyond the archival textual record (Throne, 2016); however, as Byrnes (2017) noted, these retrospective stories can be analyzed and represented in a nonhierarchical and non-dominant manner by leveling the respective voices of researcher, subject, and the literature, or in this case, the additional voice of Hauberg as interpreter/recorder of Mary's experiences.

Mary Kakaque Piquano Mack was an infantresiding in Indian territory when she and her family were forced to cede tribal land to the U.S. Government and identify with a native tribe under the Dawes Commission as a final act of land dispossession for Black Hawk's descendants and other Native Americans, policy that dispossessed them of a reported 80 million acres by 1934 (Zimmer, 2014). Native American land dispossession occurred through governmental legislation, forced removals, allotments, and eminent domain (Fitzgerald, 2015), and for Black Hawk's family, this involved multiple actions including forced removal, negotiation for Black Hawk and his wife to remain in lowa, and allotments for his children and their families in Indian territory. According to Hauberg's notes, Mary was educated at the Haskell Institute, an American Indian boarding school in Lawrence, Kansas, established under federal assimilation policy that may or may not have given Mary agency (Gunn Allen, 1986)and a sense of cultural self-determination as $21^{\text {st }}$ century studies of these schools from native perspectives have shown, in contrast to the previous century critiques of the tragic prejudices that utilized education of children as a vehicle to annihilate tribal and cultural identity, destruction of essential cultural and religious anchors, and other horrors of calculated assimilation techniques (Davis, 2001; Smith, 2001; Vučković, 2008).

Mary's letter to Hauberg illustrates that the education did provide her with the ability to read and write, skills, according to Hauberg, her father, grandfather, and great grandfather likely did not possess. While much has also been written in recent years about appropriation of others' experiences and culture (Brown \& Kanouse, 2015), researchers cannot ignore when drawn to

\footnotetext{
${ }^{2}$ Simonsen (2011) presents an exhaustive and insightful analyses of the Black Hawk descendants' photographs within Hauberg's "Indian Notebooks" collection and noted "Hauberg's visits to the Sauks suggest that part of indigenous meaning making in the early twentieth century may have rested on some individuals' consumption and display of images and artifacts of the "Indian" originally produced for white audiences" (p. 319) while Mary's family may have also viewed these photographs as opportunity for selfconstruction.
} 
a research focus of a woman who lived in the past. Or perhaps when researcher reflexivity is necessary to bring forward archival narrative data of a contemporaneous voice recorded in a past lived history (Byrne, 2017; Foley, 2002; Nencel, 2014). This continued observation of another's experiences with dispossession to better inform and understand our own must engage responsibility for fidelity of observation. It is with rigorous fidelity of analysis that brings forward clarity and disclosure of researcher positionality as lens to offer inference and interpretation of observations. It is these processes that are informed by positionality -whether subtle or overt.

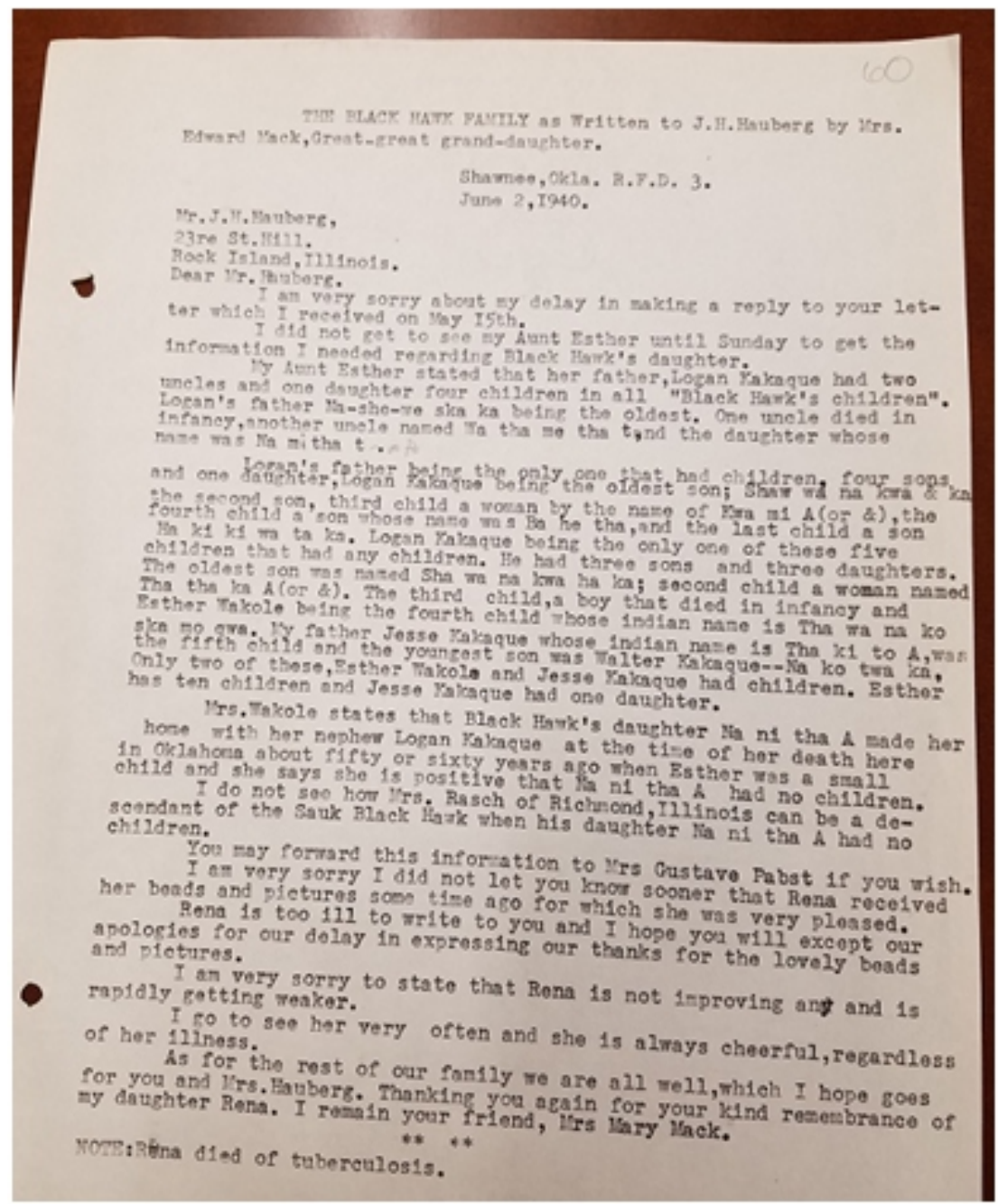

Figure 1 Transcribed letter from Mary (Kakaque) Mack to John Henry Hauberg, June 2, 1940. Courtesy Augustana Special Collections

As Bettez (2012) noted, the complexities of cultural norms can be observed and cultural coopting, or what (Hoskins, 2015) refers to as "the power to position," (p. 404) can be mitigated through genuine consideration and respect, attributes found in the fidelity of researcher positionality as a precursor to data collection and analysis. In spite of Mary's lineage as Black Hawk's direct descendant, no biography of her life story exists beyond Hauberg's interpretations, and while the reader is left with the letter she wrote to him, her penmanship and envelope postmark not retained. As such, the letter was analyzed as transcribed and represented as one Native woman's posthumous voice, perhaps protected in archive by the very privilege to land tenure that influenced her family's removal from it and relocation to elsewhere.

\section{Fidelity, Researcher Positionality, and Narrative Voice}

As noted, researcher positionality must be considered within the multi-faceted, complex, and necessary structures surrounding qualitative inquiry, specifically in this study from a feminist narrative perspective, before it can or even should be engaged (Bourke, 2014; Blakely, 2007; Throne, 2012; Woodiwiss, Smith, \& Lockwood, 2017). For this study, a 
definition of researcher positionality relied upon prior work by Bourke (2014), Throne (2012, 2018a, 2018b), and Bowlin, Buckner, and Throne (2016) over the past two years informed the inquiry to consider an authentic other narrative voice and to assess the fidelity of self as researcher and self-identified researcher positionality throughout the inquiry to dissect another's language to recount narrative voice as remnant of dispossession (Throne et al., 2018). This definition subscribes to the identification of one's positionality as a necessary process of a principal investigator for critical self-reflection and a determination of this selfawareness within the social constructs, biases, contexts, layers, power structures, identities, transparency, objectivity and subjectivities for the viewpoint assumed within the research (Bourke, 2014; Bowlin et al., 2016; Throne, 2012; Throne et al., 2018).

Further, Ruuska (2017) noted how memory manifests in relation to place as dependent upon multiple factors, including researcher positionality, and the contextualities of environment and time, and moreover how these contextual attributes allow for multiplicity in meaning, interpretation, and ultimately contextual truth. Likewise, Milner (2007) informed this perspective of researcher positionality as a lens to view the other through disruption to ensure narrative voice is viewed devoid of dominance and leveled by implications of any power dynamics and hierarchical positions (Filep et al., 2017). This acknowledgement is necessary to the role and potential influence of researcher bias, position, or hierarchy as a critical reduction within narrative research protocol whereby acknowledgement of biases and subjectivities remain necessary as products of individual positionalities, and qualitative researchers may consciously engage themselves apart from their subjects of inquiry (Throne et al., 2018). Without these declarations, the work may be suspect and incomplete.

Researcher consciousness of self and subsequent declarative viewpoint allows for more transparent inquiry into the experience of the other and reduces the dangers of filtering data via researcher perspectives that are blind to racialized and cultural patterns existent within the dataset (Milner, 2007) or those perceived as appealing to an audience's sentimentality (Mielke, 2002) such has been noted for the Native American lived experience amidst generational acculturation or for descendants who continued to live amidst policy consequences of removal and subsequent acculturation and assimilation policy (Bataille \& Mullen Sands, 1984; Gunn Allen, 1986; DeMarni Cromer et al., 2018). Or even more horrendous, as some researchers have noted, the aftermath of an intentional extermination or policy for legalized genocide (Anderson, G. C., 2016; Gunn Allen, 1986; Ostler, 2016) therefore, the responsibility of fidelity rests with researcher positionality, and an essential aspect of the integrative process is to assess the multiple identities as practitioner, scholar, and investigator as the fidelity of research positionality rests upon the multifaceted, complex, and necessary structures within the narrative data as spatiotemporally situated (Bowlin et al., 2016; Throne, 2012; Throne et al., 2018).

\section{Method and Framework}

Ultimately, Leavy's coherence served as a framework in the collection and narrative content analysis of the data gathered in fall 2017 from the J.H. Hauberg collection maintained by Special Collections at the Thomas Tredway Library, Augustana College, in Rock Island, IL. Leavy (2015) credits Barone and Eisner's (2012) six components for evaluation of arts-based research as the basis for consideration of coherence, and further utilizes coherence as a component of the aesthetic quality or aesthetic power in the presentation of the essence of the issue in a coherent form to achieve this aesthetic power (Leavy, 2017a; Leavy, 2017b). Within this framework, form and content must be closely aligned to achieve narrative coherence for feminist research (Leavy, 2013), which was a dependable and relevant frame for this narrative inquiry into the phenomenon of dispossessed voice of one of Black Hawk's female descendants.

The narrative data comprised to form a coherent narrative whole prior to analysis and the representation of results as rendered via redaction and reduction using a feminist research lens as a particular form of coherence to distinguish the perspectives self and other, researcher and researched, observer and observed (Leavy, 2013; Taylor, 2013; Throne, 2018a, 2018b). More importantly, this coherence framework must also be coupled with fidelity and leveling of researcher positionality, as noted earlier, if Mary's experiences are to be transferable to the experiences and explanation of phenomena within the living generations of Black Hawk's descendants, especially for Black Hawk's female descendants, and contribute 
to the current scholarship of this target population and emerging understanding of the legacy of acculturation and assimilation (Berryman et al., 2013).

As Fitzgerald (2015) noted, these disparate voices can eventually form a coherent whole by which to better understand the lived experience from a gendered perspective, and that the disparate can emerge as a coherent multiplicity of voices. My own researcher positionality was informed by an ancestry of European and Scandinavian immigrants who settled the Midwest on land parcels forcibly vacated by these native peoples while my viewpoint issituated within an aesthetic and epistemology rooted in feminist principles and a researchbased understanding of the complexities of land culture as curators for the spiritual and relational aspects of earth and coastal access (Throne, 2016; Throne, 2018a) along with a necessity for process internalization, challenges to assumptions, and reflexivity in ongoing research-based inquiry. Likewise, Fletcher(2014) posited a privileged ontological position exists for white; yet, also noted white is panoptic with an inherent power for invisibility and observation. This coupled with reflexivity as I accessed images and narrative text to open an epistemological vantage point to consider shifting gender and cultural power dynamics and the complexities of an era of acculturation that Mary lived within amid those that continue to be reconsidered today (Woodiwiss et al., 2017).

Coherence was also utilized within the processes of data collection and analysis as well as for presentation of findings made possible by consideration of Hauberg's notebooks and images as retrospective to illustrate Mary's life experience (Leavy, 2017a). Consideration in data collection was also given to Hauberg's interviews with individuals one, two, and three generations removed from Black Hawk and Mary in Hauberg's efforts to reconstitute the unrecorded experiences they did not know or acquire and were his interviews a form of social reproduction and contextualized by the prominent dominant culture who may marginalize or ignore even contemporary writing by Native women, particularly writing with implications for gender and race (Anderson, 2016; Bataille \& Sands, 1984; Fitzgerald, 2015). Similarly, Hauberg's interviews to construct a Black Hawk lineage and native history of Rock Island County were primarily conducted with Black Hawk's male descendants, including Mary's father, grandfather, and great grandfather, which limited record of the female descendant experience (see Figure 2); however, his notes and paraphrases did include third-person interactions with Mary including photographs at various life stages (Simonsen, 2011).

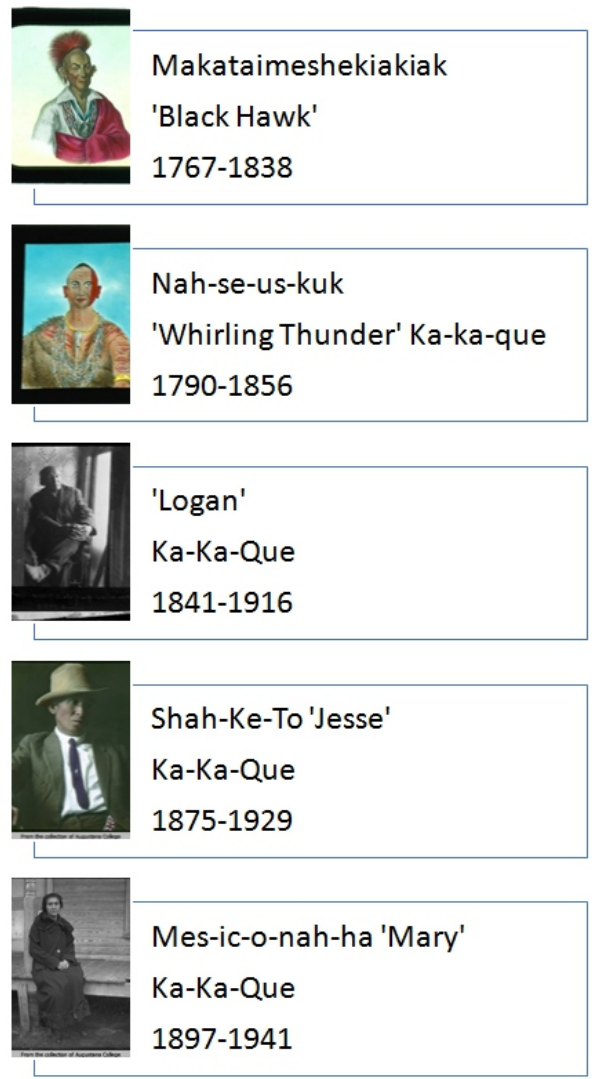

Figure 2. Black Hawk to great-great granddaughter, Mary Kakaque. Images courtesy of Augustana Special Collections. Image (c)Augustana College 
To illustrate these constructs and framework, the singular narrative correspondence was first analyzed, a personal letter presumed to be penned by Mary to Hauberg dated June 2, 1940 , as subsequently transcribed by Hauberg or an unknown typist. It is important to note that Mary died some months later in 1941 with internment in the Tecumseh Cemetery in Shawnee, Oklahoma, and buried within no visible proximity to other Black Hawk descendants or her own children.

\section{Redaction, Reduction, and Representation}

In Whereas, poet Layli Long Soldier (2017) masterfully depicts the reduction and the redaction of words that starkly remind us that the voice of the experience is often the words of the dominant culture, those who wrote on behalf of an experience and not the words of the individual, the actual direct voice of the experience with dispossession, acculturation, assimilation, and the like (Berryman et al., 2013). When redaction, reduction, and representation are considered for Mary's words, the few that exist in the Hauberg collection are assumed to be from Black Hawk's direct descendent, a woman educated within an educational system imposed by the dominant culture; yet, still we are left with wordsretyped by Mary's interpreter, a white man of privilege who paraphrased each meeting with her, her father, and her grandfather, and no original words in her own longhand remain for comparison, which may have shown whether redaction or reduction or worse, omission, of her words was done-speaking for her or rather of her and a verbatim transcription of the original letter, without Hauberg's footnote, may exist.

I am very sorry I did not let you know sooner that Rena received her beads and pictures some time ago for which she was very pleased. (\8)

Rena is too ill to write to you and I hope you will except (sic) our apologies for our delay in expressing our thanks for the lovely beads and pictures. (\$9)

The double contrition may actually be reflective of the gratitude of Mary to Hauberg over more than the recent gift to her daughter, but over the many gifts to her family over years including funds to travel to her grandfather's birthplace in Illinois. As Simonsen (2011) noted, "Hauberg invited local audiences to sympathize with Black Hawk by emphasizing the leader's attachment to the land, his love for the Sauks, and the role of the 1832 Black Hawk War in ending what Hauberg regarded as the idyllic community rooted at Saukenuk" (p. 302); yet, it is unknown whether these sentiments were Mary's own or imparted by her father or her grandfather and even more remote in Hauberg's papers are the voices of mother and grandmother. Or further, great grandmother and Black Hawk's wife, Asshewaqua or "Singing Bird," Mary's great great grandmother and mother of Black Hawk's daughter, a genealogical thread Hauberg still sought at the time of the 1940 letter. Mary shifts from mother to reporter to share this oral history.

Mrs. Wakole states that Black Hawk's daughter Na ni tha A made her home with her nephew Logan Kakaque at the time of her death here in Oklahoma about fifty or sixty years ago when Esther was a small child and she says she is positive that Na nit ha A had no children. ( 15$)$

I do not see how Mrs. Rasch of Richmond, Illinois can be a descendant of the Sauk Black Hawk when his daughter Na nit ha A had no children. (\$6)

While written in near proximity to Hauberg's correspondences to her, Mary's narrative voice was filtered through the lens of the other as it was transcribed to Hauberg's typewritten page. As historical scholar, Hauberg's desire for accuracy, authenticity, in addition to the trustworthiness of the data he gathered from Black Hawk's descendants. Yet, his simple penand-ink edits must be considered as likely hierarchical from a position of privilege whereby a feminist narrative approach is responsible to explore the letter from Mary's perspective rather than Hauberg's (Hesse-Biber, 2007), but one Simonsen (2011) noted as perhaps filtered by a Haskell educational experience as part of acculturation and assimilation, or the generational traumas, Brave Heart (1998; as cited in DeMarni Cromer et al., 2018) and others have referred to as the historical trauma of the American Indian holocaust, genocide, or ethnic cleansing (Anderson G. C., 2016; Gunn Allen, 1986; Ostler, 2016).

I am very sorry to state that Rena is not improving andy (typed correction) and is rapidly getting weaker. (\$10)

While some critiques of Native American personal narratives have stigmatized them as 
sentimental, an emotional appeal that is pathos due to circumstance, time, and audience (Mielke, 2002) whereby the vehicle of personal narrative itself is a lived experience that emotion, circumspection, reflection, and reflexivity are vital aspects of the personal narrative or autobiographical genre, and of course essential to feminist narrative research; however, as Blakely (2007) noted they provide "a more holistic study, a richer and more accurate analysis of the research, and, ultimately, a deeper understanding of the construction of knowledge on emotionally charged topics" (p. 62) when emotion, reflexivity, and positionality are considered for researcher, other, and ancillary voices gathered within the narrative data (Nencel, 2014). The experience is further contextualized as to Mary's experiences with grief and loss when considered within Simonsen's (2011) earlier characterization of Mary's prior loss of another child and the resilience necessary to carry on. This expanded yet still limited knowledge of Mary's overall lived experience with acculturation and assimilation as direct female descendant of Black Hawk may be further narrowed had Hauberg not added the footnote in transcription, which provided a deeper context to Mary's ongoing experiences with loss and grief.

From this perspective, Mary's voice and tone remain devoid of emotion, a more neutral stance, especially in consideration of the two primary objectives of communication: first, her familial knowledge of Black Hawk's daughter, a history that Hauberg spent decades constructing, and second, her suffering child, Rena thereby leaving the reader to deal with the sudden impact of dramatic irony in retrospect.

\section{NOTE: Rena died of tuberculosis. (Hauberg's footnote)}

\section{Conclusions}

The fidelity of researcher positionality in the exploration of posthumous narrative archives carries a two-fold responsibility for authentic consideration and respect, without which the work may be suspect and incomplete. Further research should consider the Haskell Institute records within the National Archives (Moravec, 2017) to better characterize Mary's educational experiences amid an era of intentional cultural annihilation, as well as an analysis of the collective narrative of Hauberg's interpretations, paraphrases, and summaries of Mary's existence through the lens of resilience as an emergent theme and existent among land cultures that experience land dispossession (Throne, 2016; Woodiwiss et al., 2017). In addition, a qualitative phenomenological study is recommended for further exploration of Mary's lived experience using the full archival Hauberg collection to consider the constructs of voice or resilience as the understanding of the lived experiences of Black Hawk's female descendants remain limited.

Further, the study findings contributed to Leavy's (2017a, 2017b) concept of coherence specific to the representation of results of the analysis of Mary's singular letter and for further consideration of voice specific to Mary's descendants, including Black Hawk's living generations of female descendants within the Sac \& Fox Nation. Arts-based research may be a method to continue to explore contemporary Native American women's experiences with voice dispossession and the legacy of land dispossession. The concept of coherence may also be an additional retrospective through arts-based research to explore the additional archival data surrounding Mary's lived experience and represented through literary forms such as creative non-fiction, poetry, or another genre.

Finally, a critical ethnographic case study may be advantageous to explore subsequent findings among Black Hawk's living generations of female descendants. Anderson K.(2016) commented on the difficult time Native American women today can have as they pursue and accomplish a sense of voice apart from a partner, a family, or their community who may silence needs or concerns. In addition, dispossession was simply an ongoing generational reality many Sauk/Sac descendants have endured due to relocation, denial of property or promises, or other realisms that have created ongoing loss, internalized racism, and deidentification. She calls for a reclamation of tradition to dilute the "Western practices that were thrust upon" generations of Native women now ready to reclaim and reinstate authentic culture and traditions ( $p .133$ ) as well as recovery of voice and personal power to move away from a Western heteropatriarchal model. Comparisons between Black Hawk's and other Sac/Sauk descendants who experienced the ancestral effects of relocation, acculturation, and assimilation (DeMarni Cromer et al., 2018), or as Simonsen (2011) referred to as familial loss and regeneration, with the perspectives of living Black Hawk female descendants through 
Mary's lineage may illustrate a contemporary perspective on voice, culture, and land dispossession.

\section{Acknowledgments}

Augustana College Thomas Tredway Library, Special Collections, and especially Special Collections Librarian, Emma Lincoln, for support in archival data collection.

\section{Author Biography}

Robin Throne, PhD, is a Professor for Northcentral University. Her research agenda continues to consider voice and land dispossession from narrative, feminist, and heuristic approaches. She is the author of Practitioner Research in Doctoral Education (Kendall Hunt, 2012) and serves on the editorial review board for the International Journal of Doctoral Studies.

\section{References}

Anderson, G. C. (2016). The Native peoples of the American West: Genocide or ethnic cleansing? The Western Historical Quarterly, 47(4), 407-433. doi:doi: 10.1093/whq/whw126

Anderson, K. (2016). A recognition of being: Reconstructing Native womanhood (2nd ed.). Toronto, ON: Canadian Scholars'Press.

Barone, T., \& Eisner, E. W. (2012). Arts based research. Thousand Oaks, CA: Sage.

Bataille, G. M., \& Mullen Sands, K. (1984). Traditional values in modern context: The narratives to come. In G. M. Bataille, \& K. Mullen Sands, American Indian women: Telling their lives (pp. 127-141). Lincoln, NE: University of Nebraska Press.

Berryman, M., SooHoo, S., Nevin, A., Barrett, T. A., Ford, T., Nodelman, D. J., . . Wilson, A. (2013). Culturally responsive methodologies at work in education settings. International Journal for Researcher Development, 4(2), 102-116. doi:10.1108/IJRD-08-2013-0014

Bettez, S. C. (2012). But don't call me White. Heidelberg, Germany: Springer.

Blakely, K. (2007). Reflections on the role of emotion in feminist research. International Journal of Qualitative Methods, 6(2), 59-68.

Bourke, B. (2014). Positionality: Reflecting on the research process. The Qualitative Report, 19, 1-9. Retrieved from: http://nsuworks.nova.edu/tqr/vol19/iss33/3/

Bowlin, L. K., Buckner, S., \& Throne, R. (2016). Duality, positionality, and stance: Workplace dissertation research as preparation for practice-based research. Twelfth International Congress of Qualitative Inquiry. University of Illinois, Urbana-Champaign. Retrieved from: http://firescholars. seu.edu /conference_proceedings/3/

Brown, N. A., \& Kanouse, S. (2015). Re-collecting Black Hawk: Landscape, memory, and power in the American Midwest. Pittsburgh, PA: University of Pittsburgh Press.

Byrne, G. (2017). Narrative inquiry and the problem of representation: "Giving voice", making meaning. International Journal of Research \& Method in Education, 40(1), 36-52. doi:http://dx.doi.org. proxy1.ncu.edu/10.1080/1743727X.2015.1034097

Davis, J. (2001). American Indian boarding school experiences: Recent studies for native perspectives. Magazine of History, 15(2), 20-22.

DeMarni Cromer, L., Gray, M. E., Vasquez, L., \& Freyd, J. J. (2018). The relationship of acculturation to historical loss awareness, institutional betrayal, and the intergenerational transmission of trauma in the American Indian experience. Journal of Cross-Cultural Psychology, 49(1), 99-114. doi:10. $1177 / 0022022117738749$

Filep, C. V., Turner, S., Eidse, N., Thompson-Fawcett, M., \& Fitzsimons, S. (2017). Advancing rigour in solicited diary research. Qualitative Research, 1-20. doi:10.1177/1468794117728411

Fitzgerald, S. J. (2015). Native women and land: Narratives of dispossession and resurgence. Albuquerque, NM: University of New Mexico Press.

Fletcher, T. (2014). 'Does he look like a Paki?'an exploration of'whiteness', positionality and reflexivity in inter-racial sports research. Qualitative Research in Sport, Exercise and Health, 6(2), 244-260. 
doi:http://dx.doi.org/10.1080/2159676X.2013.796487

Foley, D. E. (2002). Critical ethnography: The reflexive turn. International Journal of Qualitative Studies in Education, 15(4), 469-490. doi:https://doi.org/10.1080/09518390210145534

Griffiths, M. (2017). From heterogeneous worlds: western privilege, class and positionality in the South. Area, 49(1), 2-8. doi:10.1111/area.12277

Gunn Allen, P. (1986). The sacred hoop: Recovering the feminine in American Indian traditions. Boston, MA: Beacon Press.

Hesse-Biber, S. N. (2007). Feminist research: Exploring, interrogating, and transforming the interconnections of epistemology, methodology, and method. In S. N. Hesse-Biber (Ed.), Handook of feminist research (pp. 2-26). Thousand Oaks, CA: Sage.

Hoskins, K. (2015). Researching female professors: The difficulties of representation, positionality and power in feminist research. Gender \& Education, 27(4), 393-411. doi:10.1080/ 09540253. 2015.1021301

Leavy, P. (2013). Fiction as research practice: Short stories, novellas, and novels. Walnut Creek, CA: Left Coast Press.

Leavy, P. (2015). Method meets Art: Arts-based research practice (2nd ed.). New York: Guilford.

Leavy, P. (2017). Research design: Quantitative, qualitative, mixed methods, arts-based, and communitybased participatory research approaches. New York: Guilford.

Long Soldier, L. (2017). Whereas. Minneapolis, MN: Graywolf Press.

Mielke, L. L. (2002). "native to the question": William Apess, Black Hawk, and the sentimental context of early Native American autobiography. The American Indian Quarterly, 26(2), 246-270.

Milner, H. R. (2007). Race, culture, and researcher positionality: Working through dangers seen, unseen, and unforeseen. Educational Researcher, 36(7), 388-400. doi:10.3102/0013189X07309471

Moravec, M. (2017). Feminist research practices and digital archives. Australian Feminist Studies, 32(9192), 186-201.

Nencel, L. (2014). Situating reflexivity: Voices, positionalities and representations in feminist ethnographic texts. Women's Studies International Forum, 43, 75-83. doi:http://dx.doi. org/10.1016/j.wsif.2013.07.018

Ostler, J. (2016). 'Just and lawful war' as genocidal war in the (United States) Northwest Ordinance and Northwest Territory, 1787-1832. Journal of Genocide Research, 18(1), 1-20.

Raheja, M. H. (2006). "I leave it with the people of the United States to say": Autobiographical Disruption in the Personal Narratives of Black Hawk and Ely S. Parker. American Indian Culture \& Research Journal, 30(1), 87-108.

Ruuska, A. K. (2017). Memory, materiality, and place in Ojibway rock art performances. In D. Bruno, \& I. J. McNiven (Eds.), The Oxford Handbook of the Archaeology and Anthropology of Rock Art. Oxford University Press. doi:10.1093/oxfordhb/9780190607357.013.54

Simonsen, J. (2011). Descendants of Black Hawk: Generations of identity in Sauk portraits. American Quarterly, 63(2), 301-335. Retrieved from:http://www.jstor.org/stable/41237549

Simonsen, J. (2016). Re-collecting Black Hawk: Landscape, memory, and power in the American Midwest . The Annals of lowa, 75(1), 71-73.

Smith, M. (2001). Forever changed: Boarding school narratives of American Indian identity in the U.S. and Canada. Indigenous Nations Studies Journal , 2(2), 57-82.

Taylor, C. S. (2013). Validity and validation. Oxford, England: Oxford University Press.

Throne, R. (2012). Positionality. In Practitioner research in doctoral education (p. 56). Dubuque, IA: Kendall Hunt.

Throne, R. (2016). Past as prologue: Sea Island Cotton as heuristic metaphor for the Port Royal Experiment. Sage Open, 6(3), 1-8. doi:10.1177/2158244016662105

Throne, R. (2018a). Voice as persona: Disinterring dispossessed women's voices from a Sac \& Fox Nation relocation and Gullah Sea island low country heirs' property. 21st Annual American Association of Behavioral and Social Sciences Conference. Las Vegas.

Throne, R. (2018b). Hermeneutic archival research \& artistic license: Exhuming dispossessed Sauk voices through creative non-fiction. 14th Annual International Congress of Qualitative Inquiry. University of Illinois, Urbana-Champaign. 
Throne, R., Bourke, B., Bowlin, L. K., Hailey, V., Joseph, S., \& Yedgarian, V. (2018). Insider/outsider, betwixt and between: Post-doc perspectives of researcher positionality after dissertation research. 2nd annual Conference on Academic Research in Education. Las Vegas.

Vučković, M. (2008). Voices from Haskell: Indian students between two worlds, 1884-1928. Lawrence, KS: University Press of Kansas.

Warren, S. (2009). "To show the public that we were good indians": Origins and meanings of the Meskwaki Powwow. American Indian Culture and Research, 33(4), 1-28. doi:https://doi.org/10. 17953/aicr.33.4.2672170008q41642

Woodiwiss, J., Smith, K., \& Lockwood, K. (2017). Feminist narrative research: Opportunities and challenges. London: Palgrave Macmillan.

Zimmer, E. S. (2014). Settlement sovereignty: The Meskwaki fight for self-governance, 1856-1937. Annals of lowa, 73, 311-347. Retrieved from:http://ir.uiowa.edu/annals-of-iowa/vol73/iss4/3 